\title{
Recent Breakdown of the Seasonal Linkage between the Winter North Atlantic Oscillation/Northern Annular Mode and Summer Northern Annular Mode
}

\author{
KOJI YAMAZAKI \\ Faculty of Environmental Earth Science, Hokkaido University, Sapporo, and Graduate School of Bioresources, \\ Mie University, Tsu, Japan \\ MASAYO OGI \\ Centre for Earth Observation Science, University of Manitoba, Winnipeg, Manitoba, Canada \\ YOSHIHIRO TACHIBANA \\ Graduate School of Bioresources, Mie University, Tsu, Japan \\ TETSU NAKAMURA \\ Faculty of Environmental Earth Science, Hokkaido University, Sapporo, Japan \\ KAZUHIRO OSHIMA ${ }^{\mathrm{a}}$ \\ Institute of Arctic Climate and Environment Research, Japan Agency for Marine-Earth Science and \\ Technology, Yokosuka, Japan
}

(Manuscript received 5 December 2017, in final form 14 November 2018)

\begin{abstract}
The summer northern annular mode (NAM) and the winter North Atlantic Oscillation (NAO)/winter NAM have a positive correlation from the mid-1960s to the 1980s. Namely, when the winter NAO/NAM is in a positive phase, the following summer NAM tended to be in a positive phase. During the period from the mid-1960s to the 1980s, the NAO/NAM signals extended to the stratosphere in winter. Also, the lowertropospheric warm anomaly over northern Eurasia in winter associated with the positive phase of NAO/NAM continued into spring. In summer, the annular anomalies in the temperature and 500-hPa height fields appeared, and the high-latitude westerly wind was enhanced following the winter positive NAO/NAM. However, after circa 1990, the seasonal linkage was broken (i.e., the winter-to-summer correlation became insignificant). The stratospheric signal in the winter NAO/NAM became weak and summer signals associated with the winter NAO/NAM almost disappeared. Seasonal evolutions of atmospheric circulation and sea surface temperature (SST) anomalies associated with the winter NAO are examined for an early good-linkage period and a recent poor-linkage period. We discuss the possible causes of the linkage breakdown such as stratospheric ozone, North Atlantic SST, and Atlantic multidecadal oscillation, besides chaotic internal variability in the climate system. Simulations with the Community Earth System Model suggest that the ocean and/or sea ice with interseasonal memories possibly cause the linkage, besides large internal variability through which the linkage can take place by chance.
\end{abstract}

\footnotetext{
${ }^{a}$ Current affiliation: Department of Radioecology, Institute of Environmental Sciences, Rokkasho, Japan.
}

Corresponding author: Koji Yamazaki, yamazaki@ees.hokudai. ac.jp

\section{Introduction}

The North Atlantic Oscillation (NAO), which is a simultaneous seesaw-like strengthening and weakening of the Icelandic low and the Azores high, has a great impact on the Northern Hemisphere climate, particularly 
on the European climate (e.g., Hurrell et al. 2003). The Arctic Oscillation (AO) or the northern annular mode (NAM) (Thompson and Wallace 2000, 2001) is the most dominant pattern in the variation of the northern extratropical circulation in winter and includes the NAO pattern over the North Atlantic region. The negative phase of the winter NAO/NAM brings a cold outbreak in Europe, East Asia, and the U.S. East Coast. The NAO/NAM changes its spatial pattern in summer and also impacts the Northern Hemisphere summer climate (Ogi et al. 2004; Folland et al. 2009; Wu et al. 2012). The summer patterns move northward compared with the winter ones, especially in the case of NAM. In summer, the NAO and NAM are distinct and have different association with the winter NAO/NAM. A large positive NAM in summer often brings an extreme heat wave in Eurasia-Europe and is accompanied by blocking highs over East Asia and Europe (Ogi et al. 2005; Tachibana et al. 2010). Prediction of the summer NAM is thus important.

The winter NAO/NAM impacts the following summer atmospheric circulation and its summer signature resembles the dominant variability in the summer extratropics (i.e., the summer NAM) (Ogi et al. 2003a, 2004). These studies found that when the winter NAO/ NAM is in a positive (negative) phase, the following summer NAM tends to be in a positive (negative) phase. The discovery of this winter-to-summer seasonal linkage provides a new perspective of the seasonal forecast of NAM. These results suggested that seasonal persistency of sea ice, sea surface temperature (SST), and continental snow cover are possible candidates for interseasonal memories, which enable the NAM to link between winter and summer.

This seasonal linkage is stronger when the 11-yr solar cycle is at the maximum (Ogi et al. 2003b). Kuroda et al. (2008) found that a significant ozone anomaly associated with the winter NAO is created in winter only in high solar years. Then the ozone anomaly persists from spring to summer and creates a temperature anomaly in the lower stratosphere through radiative heating due to absorption of solar ultraviolet radiation by ozone. Such a temperature anomaly in the lower stratosphere enforces tropospheric circulation changes in the midand high latitudes in summer (Kuroda et al. 2008). Further the specific role of ozone anomaly in summer has been examined. The anomalous heating due to increased ozone in the lower stratosphere intensifies the atmospheric static stability and thus modifies synoptic wave activity in the upper troposphere. The anomalous synoptic wave activity enforces tropospheric circulation changes as like the negative summer NAM pattern (Nakamura et al. 2009). Thus, the stratospheric ozone is an additional candidate explaining the winter-to-summer linkage along with sea ice, SST and snow cover. Of course, the internal variability of the climate system alone has the possibility to cause the seasonal linkage by chance.

A recent global climatic change, such as the dramatic decrease of Arctic sea ice, might break this seasonal linkage. Winter sea ice and nearby SST anomalies might not persist until summer and lose the winter memory. The year 2010 is an example of broken years. While a strong negative phase of NAO/NAM was observed in the winter 2009/10, the NAM changed to a strong positive phase in the following summer (Otomi et al. 2013; see also Fig. 1a). Associated with the negative NAO/NAM in the winter 2009/10, cold weather was experienced in midlatitudes, while a severe heat wave occurred in western Russia in the summer of 2010 and was associated with the positive summer NAM (Otomi et al. 2013).

The main purpose of this study is to reexamine the winter-to-summer seasonal linkage found by Ogi et al. (2003a) by using a longer reanalysis dataset. We found the recent breakdown of the seasonal linkage, and the main purpose is to report this decadal change in the seasonal linkage. We examine statistics of the abovementioned possible candidates that are responsible for the seasonal linkage and discuss their roles in the seasonal linkage. We mainly focus on the observational analysis of the seasonal linkage during the past six decades and consider what might weaken the linkage. In addition, results of long climate model simulations are used for testing internal climate variability on the seasonal linkage and assessing the robustness of the seasonal linkage.

\section{Data and method}

We use monthly mean atmospheric data from 1948 to 2016 from the NCEP-NCAR reanalysis (Kalnay et al. 1996). The seasonally varying NAM (SV NAM) is the first EOF pattern in each month calculated from the zonal-mean geopotential height in the northern extratropical troposphere from 200 to $1000 \mathrm{hPa}$ (Ogi et al. 2004). The SV NAM index is calculated by using the abovementioned NCEP-NCAR data and available from the following site at Hokkaido University (http://wwwoa. ees.hokudai.ac.jp/people/yamazaki/SV-NAM/index.html). Indices of the winter [December-February (DJF) mean] NAM and the summer [June-August (JJA) mean] NAM are based on this SV NAM index.

The monthly mean NAO index is downloaded from the Climate Prediction Center/National Weather Service site (http://www.cpc.ncep.noaa.gov/products/precip/CWlink/ pna/nao.shtml). The period is from 1950 to 2016. This 

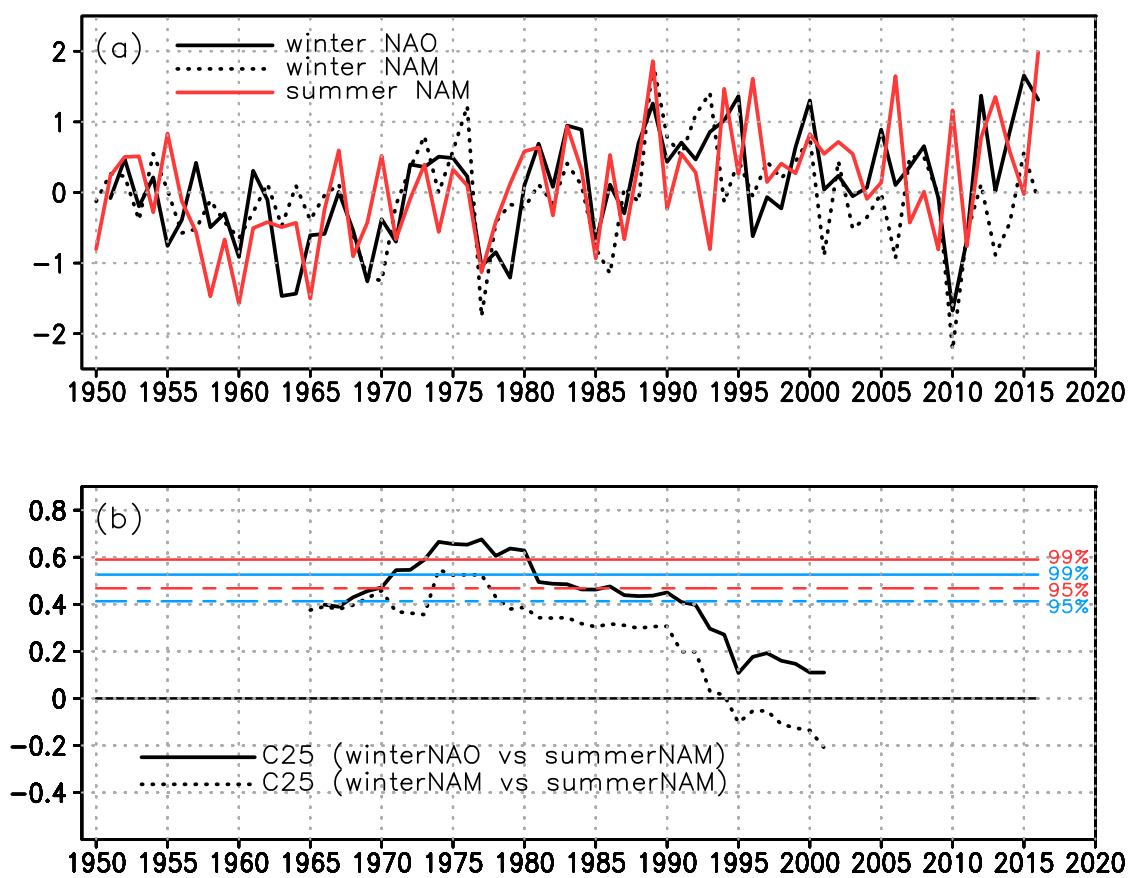

FIG. 1. (a) The time series of winter NAO (black solid line), winter NAM (black dotted line), and summer NAM (red solid line). (b) The 25-yr sliding correlation coefficient (C25) between the winter NAO index and the following summer NAM index (black solid line) and the same correlation coefficient between the winter NAM and the following summer NAM index (black dotted line). Years denote the central year of the 25-yr window (e.g., the correlation coefficient from 1966 to 1990 is plotted at 1978 of the $x$ axis). The thin red solid (dashed) line denotes the $99 \%$ (95\%) significance level for winter NAO and summer NAM. The thin blue solid (dashed) line denotes the $99 \%$ (95\%) significance level for winter NAM and summer NAM.

NAO index is based on the rotated principal component analysis of 500-hPa height field in the Northern Hemisphere north of $20^{\circ} \mathrm{N}$ (Barnston and Livezey 1987).

The SST and sea ice concentration data used in this study are the Hadley Centre Sea Ice and Sea Surface Temperature dataset from 1966 to 2015. For SST we used HadISST.1 (Rayner et al. 2003), and for sea ice we used HadISST.2 (Titchner and Rayner 2014). We use monthly mean ozone mixing ratio data from the European Centre for Medium-Range Weather Forecasts (ECMWF) interim reanalysis (ERA-Interim) (Dee et al. 2011; Dragani 2011). The ERA-Interim data start from 1979. So we use the ozone data from 1979 to 2015. As for the Atlantic multidecadal oscillation (AMO), we obtain the data from the NOAA site (http://www.esrl. noaa.gov/psd/data/timeseries/AMO/) for 1950-2016.

The sunspot number data have been obtained from the World Center for Sunspot Index and Long-term Solar Observation (WDC-SILSO), Royal Observatory of Belgium, Brussels (http://www.sidc.be/silso/datafiles; Clette et al. 2014). We used monthly total sunspot numbers from 1950 to 2016. Note that a new data series was released in 2015 (Clette et al. 2014) and we used the new data.
Two types of long-term control simulations provided by the Community Earth System Model (CESM) are used (Kay et al. 2015; http://www.cesm.ucar.edu/). One is the 2600-yr integration of the preindustrial atmospheric general circulation model (CESM-AGCM), in which boundary forcings such as the SST and sea ice are prescribed as the climatological annual cycle and no interannual variations are given. The other is the $1800-y r$ integration of the preindustrial ocean-atmosphere coupled model (CESM-CGCM). In both preindustrial simulations, the external forcings such as greenhouse gas and solar flux are also fixed at the year 1850. In addition, large ensemble historical integrations of the CESM-CGCM with 35 members from 1920 to 2005 are used. In this historical simulation, well-mixed greenhouse gases, shortlived gases, aerosols, and ozone forcing are prescribed according to observations. For simplicity, the NAO index for the CESM simulation data is defined here as the difference between the SLP at Portugal $\left(40^{\circ} \mathrm{N}, 10^{\circ} \mathrm{W}\right)$ and Iceland $\left(64^{\circ} \mathrm{N}, 20^{\circ} \mathrm{W}\right)$. Specifically, we computed the DJF mean index using the respective monthly mean SLP standardized for each month. Also, the summer NAM index for the data is defined as the difference between the 
$40^{\circ}-60^{\circ} \mathrm{N}$ and $70^{\circ}-90^{\circ} \mathrm{N}$ averages in the zonally averaged SLP. The NAM index is standardized for each month. Then, the JJA mean is calculated from the monthly index.

Significances of the correlation and regression coefficients are estimated according to a two-tailed Student's $t$ test. The effective decorrelation time $T_{e}$ for correlation between the winter NAO and summer NAM is estimated following the method shown by Metz (1991). For estimating statistical significance with two-dimensional field data, we use the Monte Carlo method. First, we made 10000 pseudowinter NAO index time series for 66 years (1951-2016) by considering 0.39 of the 1-yr lag. Then, correlation coefficients between observed fields and pseudowinter NAO indices are calculated and the coefficients are sorted in order. We calculate percentiles where observed correlations are located in 10000 members. In this way, local statistical significance is estimated.

\section{Results}

\section{a. Recent breakdown of seasonal linkage}

A series of papers (Ogi et al. 2003a,b, 2004) demonstrated that the winter NAO/NAM affects the following summer atmospheric circulation and the positive winter NAO/NAM tends to be followed by the positive summer NAM. The time series of the winter NAO/NAM indices (black lines) and the summer NAM index (red line) are shown in Fig. 1a. Between 1970s and 1990s, winter NAO/NAM and summer NAM indices vary in a similar fashion, confirming our previous studies. However, the correlation seems to be weak and negative in the most recent two to three decades. To show the decadal variation of the seasonal link, sliding correlations on a 25 -yr moving window (hereafter the 25 -yr sliding correlation C25) between the winter NAO/NAM and the summer NAM are shown in Fig. 1b. It shows high correlations in the early period, while the correlation quickly drops in recent decades. The seasonal linkage is also insignificant before the mid-1960s, which will be discussed later. The choice of a 25 -yr correlation is arbitrary, but the results do not change when the period is a little shorter or longer.

Overall, the correlation with the winter NAO is better than that with the winter NAM. Thus, we focus on the seasonal linkage between winter NAO and summer NAM hereafter. The effective decorrelation time $T_{e}$ for the correlation between winter NAO and summer NAM is estimated to be about 1.41 years (Metz 1991). Thus, the effective sample size $\left(N_{e}=N / T_{e}\right.$, where $N$ is 25 in this case) is about 16 . The strongest 25 -yr sliding correlation is 0.701 for the period $1968-1992$ for winter NAO versus summer NAM, and the correlation is significant at $99 \%$. On the other hand, the weakest one is -0.119 for 1991-2015. We define the period 1991-2015 as the recent poor-linkage period, and 1966-90 as the early good-linkage period. Note that we shift the early period for 2 years to avoid overlapping between the two periods. The correlation for the period 1966-90 is as high as 0.682 , which is also significant at $99 \%$. In the subsequent three sections, we compare atmospheric and SST fields associated with winter NAO between the two periods. The results with winter NAM are qualitatively similar to the results with winter NAO.

In the following, the regression maps with the winter NAO will be shown. The maps are interpreted as the fields associated with the positive winter NAO. Since the regression analysis is linear, the fields associated with the negative winter NAO are those with reversed sign.

\section{b. Atmospheric horizontal patterns}

Seasonal evolutions of atmospheric temperature and circulation following the positive winter NAO are presented for the early good-linkage period (1966-90: 25 years) and the recent poor-linkage period (1991-2015: 25 years) in this section.

We first examine circulation patterns for the early period. In winter, the Z500 regression in the early period shows a north-south seesaw straddled over the North Atlantic Ocean. Positive values extend zonally from the U.S. West Coast to the Russian Far East (Fig. 2a). The lower-tropospheric air temperature also shows a similar signature except for the stronger negative values over North Africa to the Middle East (Fig. 2d). In spring, the NAO-like signature remains with smaller amplitude (Figs. 2b,e). Positive values in Z500 and T850 off Newfoundland, the North Europe-Barents Sea region, and Siberia remain. Warm signals over northern Eurasia are consistent with reduced snow anomalies (Ogi et al. 2003a). Also, negative values over Greenland continue from winter, though they are small in spring. In summer, negative values over the Arctic Ocean are surrounded by positive values in both Z500 and T850 fields (Figs. 2c,f). The summer pattern is annular with large positive values over Canada, central Europe, western Russia, and the Russian Far East. The pattern is similar to the so-called summer NAM, which shifts poleward compared with the winter NAM.

In the recent period, the winter signature shows a similar NAO signature with the early period (Figs. 3a,d), though the warm values over Siberia are small and about half of that in the early period. The spring signal is weak in the recent period and the signal almost diminishes (Figs. 3b,e). The summer signal shows patchy negative regions in the midlatitude and does not resemble the 

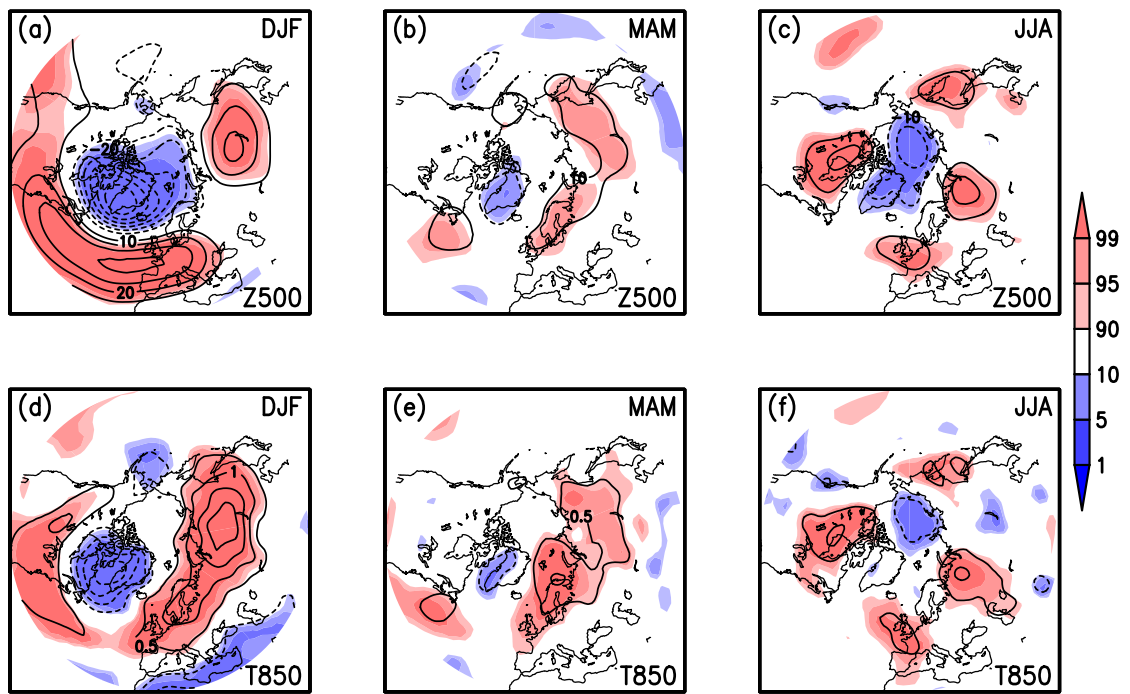

FIG. 2. (a)-(c) Geopotential height at $500 \mathrm{hPa}(\mathrm{Z} 500 ; \mathrm{m})$ and (d)-(f) air temperature at $850 \mathrm{hPa}(\mathrm{T} 850 ; \mathrm{K})$ regressed on the DJF-mean NAO for the 25-yr period from 1966 to 1990 (contours). (a) DJF-mean Z500, (b) MAM-mean Z500, (c) JJA-mean Z500, (d) DJF-mean T850, (e) MAM-mean T850, and (f) JJA-mean T850. Contours are regression coefficients. Zero contours are omitted. The contour interval for Z500 is $10 \mathrm{~m}$ and that for T850 is $0.5 \mathrm{~K}$. Statistical significance is assessed by the 10000 -member Monte Carlo simulation (shading). Correlation values of which percentiles are greater (less) than $90 \%(10 \%), 95 \%(5 \%)$, and $99 \%(1 \%)$ are shaded in gradually darker red (darker blue) color.

summer NAM at all (Figs. 3c,f). From the viewpoint of "field significance" (Wilks 2016), the spring and summer patterns in the recent period are not significant at all.

\section{c. Meridional cross sections of zonal wind, temperature, and ozone}

Figures 4 and 5 show the zonal-mean zonal wind $[U]$ and temperature $[T]$ regressed on the winter NAO for the early period and the recent period, respectively. In winter, the zonal-mean zonal winds in the troposphere are similar in both the early and recent periods, but the stratospheric signal in the early period (Fig. 4a) is stronger than that in the recent period (Fig. 5a). Also, the negative temperature centered in the Arctic lower stratosphere in the early period (Fig. 4d) is much larger than that in the recent period (Fig. 5d), indicating stronger
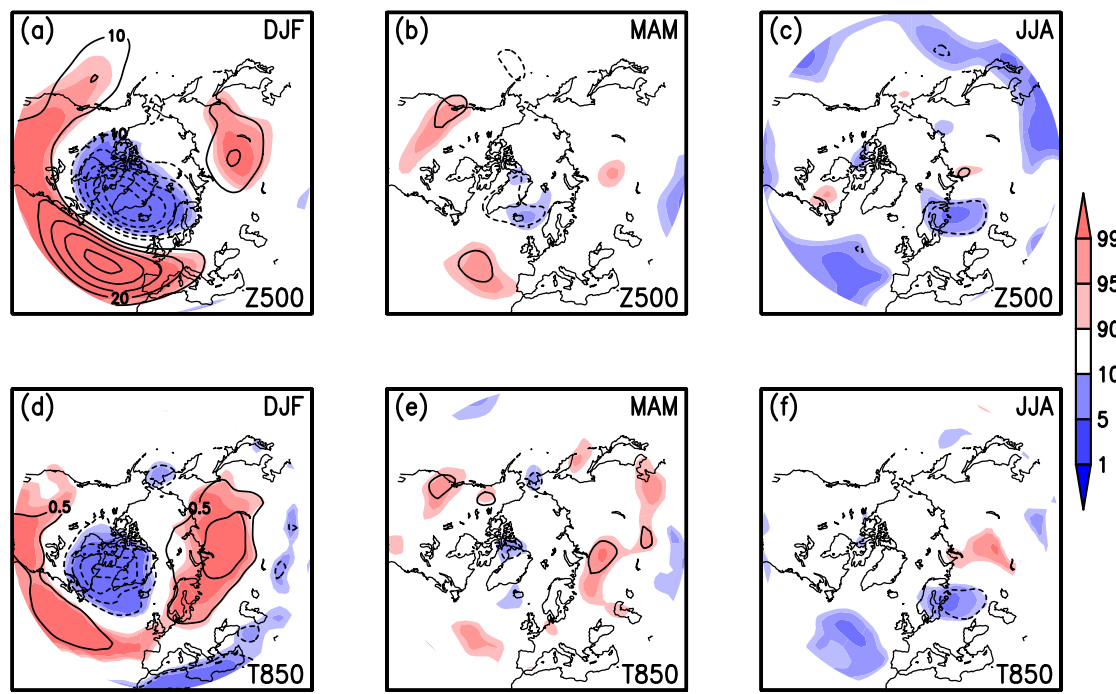

FIG. 3. As in Fig. 2, but for the 25-yr period from 1991 to 2015. 


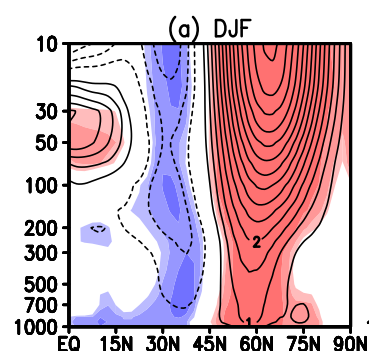

(d) DJF

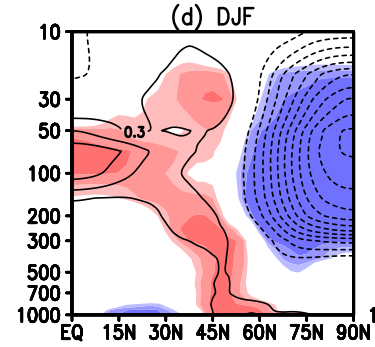

(b) MAM

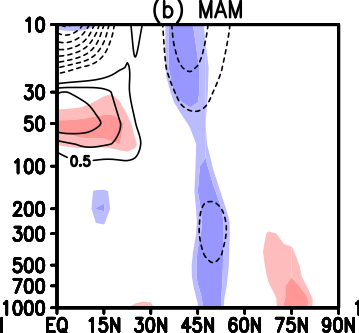

(e) MAM

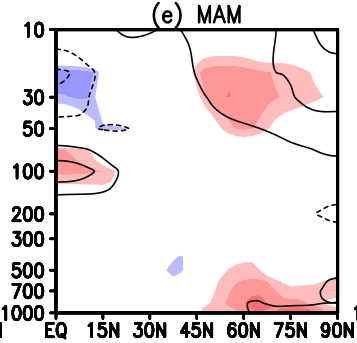

(c) JJA

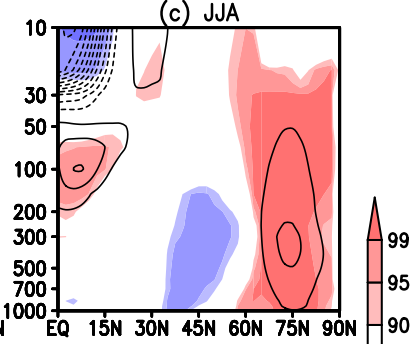

(f) JJA

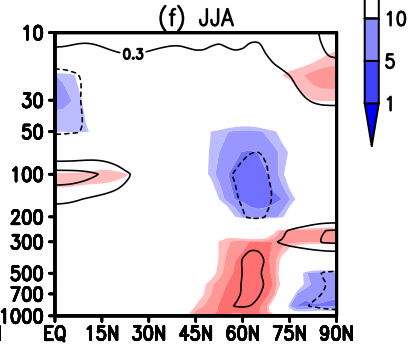

FIG. 4. (a)-(c) Zonal-mean zonal wind $[U]\left(\mathrm{m} \mathrm{s}^{-1}\right)$ and (d)-(f) zonal-mean temperature $[T]$ (K) regressed on the DJF-mean NAO for the 25-yr period from 1966 to 1990 (contours). (a) DJF-mean $[U]$, (b) MAM-mean $[U]$, and (c) JJA-mean $[U]$. (d)-(f) As in (a)-(c), but for $[T]$. Contours are regression coefficients. Zero contours are omitted. The contour interval for $[U]$ is $0.5 \mathrm{~m} \mathrm{~s}^{-1}$ and for $[T]$ is $0.3 \mathrm{~K}$. Statistical significance is assessed by the 10000 -member Monte Carlo simulation (shadings). Correlation values of which percentiles are greater (less) than $90 \%(10 \%), 95 \%(5 \%)$, and $99 \%(1 \%)$ are shaded in gradually darker red (darker blue) color.

troposphere-stratosphere coupling in the early period. In spring, very small negative values in $[U]$ are seen in the midlatitude troposphere and stratosphere in both periods (Figs. $4 \mathrm{~b}$ and $5 \mathrm{~b}$ ). For temperature [T], near-surface warm values are seen at high latitudes in the early period (Fig. 4e), while very small warm values are seen at the midlatitude near-surface layer in the recent period (Fig. 5e). This is consistent with the horizontal distribution of surface signals in Figs. 2e and 3e. In summer, large positive $[U]$ values reemerge in the high-latitude troposphere in the early period (Fig. 4c), accompanied by a pair of stratospheric cold and tropospheric warm values in $[T]$ around $60^{\circ} \mathrm{N}$ (Fig. 4f). On the other hand, virtually no signal appears in the high latitudes in the recent period (Figs. 5c,f).
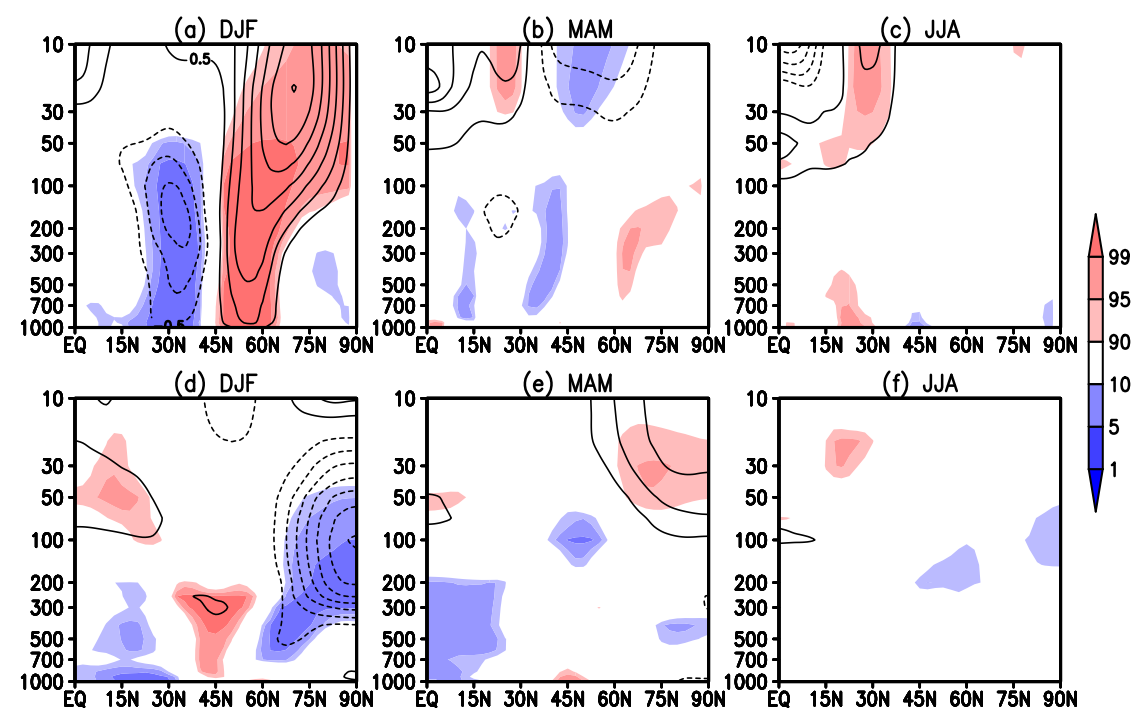

FIG. 5. As in Fig. 4, but for the 25-yr period from 1991 to 2015. 

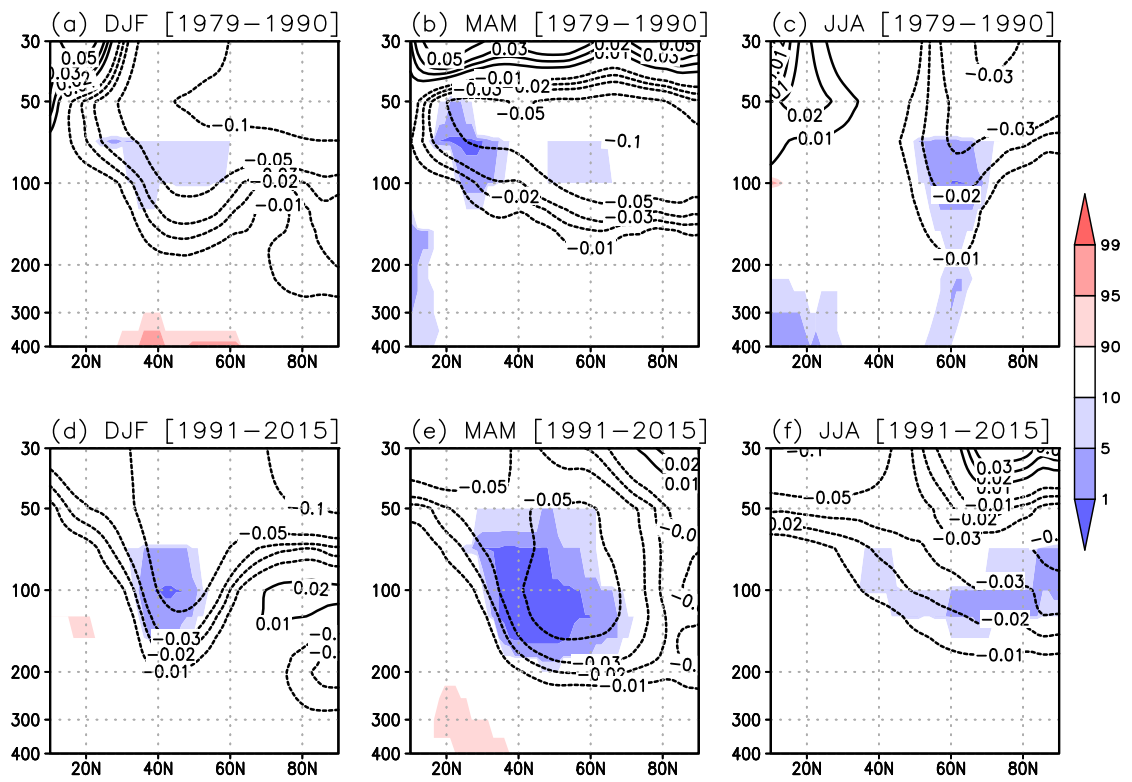

FIG. 6. Zonal-mean ozone mixing ratio regressed on the DJF-mean NAO. The contour is the mixing ratio (ppmv) and the shading shows statistical significance. (a) DJF mean, (b) MAM mean, and (c) JJA mean for the 12-yr period from 1979 to 1990 . (d)-(f) As in (a)-(c), but for the 25-yr period from 1991 to 2015. The contours are $\pm 0.01, \pm 0.02, \pm 0.03$, \pm 0.05 , and \pm 0.1 . Statistical significance is assessed by the 10000 -member Monte Carlo simulation (shading). Correlation values of which percentiles are greater (less) than $90 \%$ $(10 \%), 95 \%(5 \%)$, and $99 \%(1 \%)$ are shaded in gradually darker red (darker blue) color.

In the winters of positive NAO/NAM, the polar night jet in the stratosphere is stronger than normal and the stratospheric ozone in the mid- to high latitudes is less than normal due to weaker Brewer-Dobson circulation (Thompson and Wallace 2000). The ozone associated with the NAO-AO has a long memory until summer (Thompson et al. 2000). The zonal-mean ozone mixing ratio regressed on the winter NAO is shown in Fig. 6, in which the abovementioned process is observed both in good and poor-linkage periods. Note that the earlier period in Fig. 6 is 1979-90, which is shorter than 1966-90 in Figs. 2 and 4. Nevertheless, the horizontal and meridional maps for the shorter period, 1979-90 (not shown), are similar to Figs. 2 and 4.

The strong winter dynamic coupling between the stratosphere and the troposphere breaks down in spring, and they become decoupled. In the summer following the positive winter NAO in the early period, negative ozone values are confined at $100 \mathrm{hPa}, 60^{\circ} \mathrm{N}$ (Fig. 6c), which corresponds to the negative temperature values there (Fig. 4f). The change in the ozone amount at 100 $\mathrm{hPa}, 60^{\circ} \mathrm{N}$ for one unit of the winter NAO index is a little more than $2 \%$ of the mean value. In the summer of the recent period, to the contrary, negative ozone around $100 \mathrm{hPa}$ spreads out over a large latitudinal extent from $30^{\circ}$ to $90^{\circ} \mathrm{N}$ (Fig. 6f). The difference in the latitudinal extent of the ozone signal might be responsible for the difference in the circulation in the troposphere, because the localized ozone in the extratropical lower stratosphere affects the tropospheric temperature and circulation in summer (Kuroda et al. 2008; Nakamura et al. 2009). However, the reason why the recent ozone regressed on the winter NAO is not localized is not clear.

The solar spectral irradiance (SSI) changes over the $11-y r$ solar cycle. The associated variability in UV increases with decreasing wavelength, reaching several percent at 200-250 nm (Ermolli et al. 2013; Rottman 1999). Contributions from the solar cycle and ozone anomaly associated with winter NAO seem to be comparable. The tropospheric circulation might respond to the combined heating anomaly in the lower stratosphere (Kuroda et al. 2008; Nakamura et al. 2009), though further studies are needed. The sunspot number (SSN) is declining after around the 1990 maximum (Fig. 7), weakening incoming ultraviolet radiation. If we restrict the high solar years (SSN is greater than 100; there are 29 years), the winter NAO-summer NAM correlation is 0.650 , which is significant at the $99 \%$ level. During the early period of 1966-90, there are 14 high solar years. On the other hand, during 1991-2015, there are 9 high solar years. In addition, Ball et al. (2018) showed that ozone in the lower stratosphere outside the polar regions had 


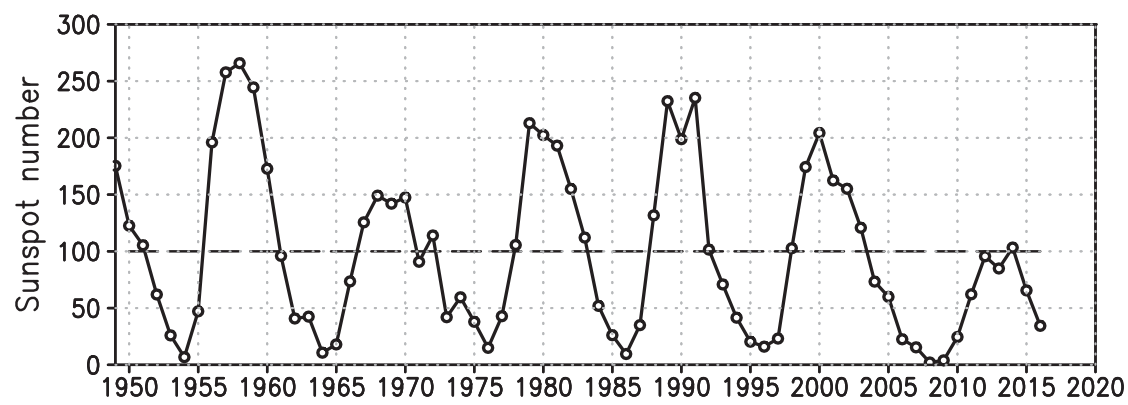

FIG. 7. The time series of the sunspot number averaged over JJA (black solid line with open circles).

continued to decline since 1998, when halogen-containing ozone-depleting substances were banned. Thus, recent less-localized and reduced ozone heating and weak solar activity might contribute to the recent breakdown of seasonal linkage.

\section{d. SST patterns associated with winter NAO}

The ocean has a large heat capacity and the SST anomaly has a long persistency compared with atmosphere.
Therefore, the SST is another possible candidate for the memory of the seasonal linkage. SST anomalies that are regressed on the winter NAO index for two 25 -yr periods are shown in Fig. 8. The NAO produces a tripole SST signal over the North Atlantic Ocean (Visbeck et al. 2003) and the tripole SST signal has a positive feedback with the NAO (Pan 2005). This tripole pattern can be confirmed in winter in both periods (Figs. 8a,d). In the early period, the positive regression
$(1966-1990)$

(a) DJF

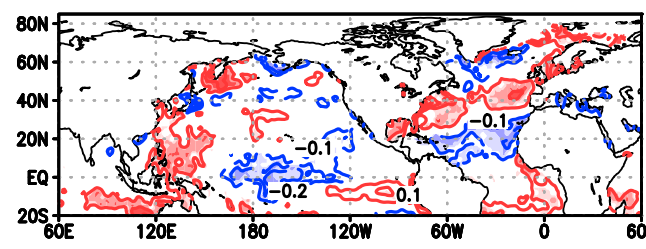

(b) MAM

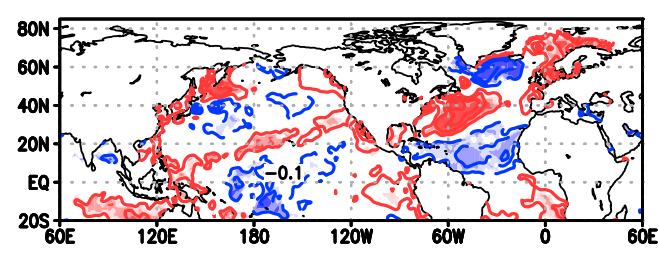

(c) JJA

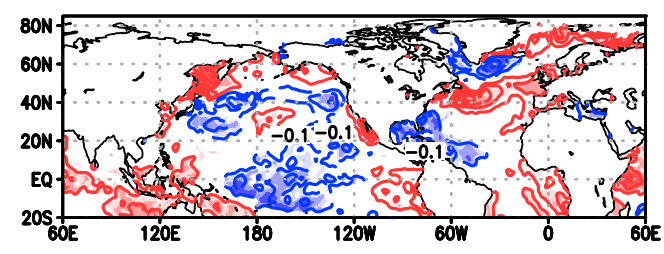

(1991-2015)

(d) DJF

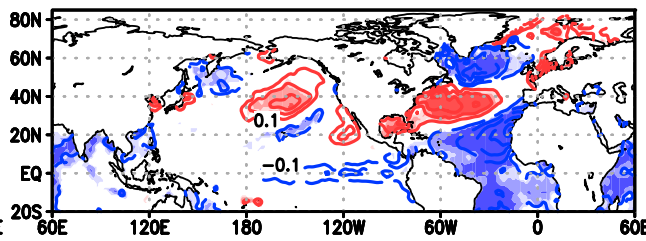

(e) MAM

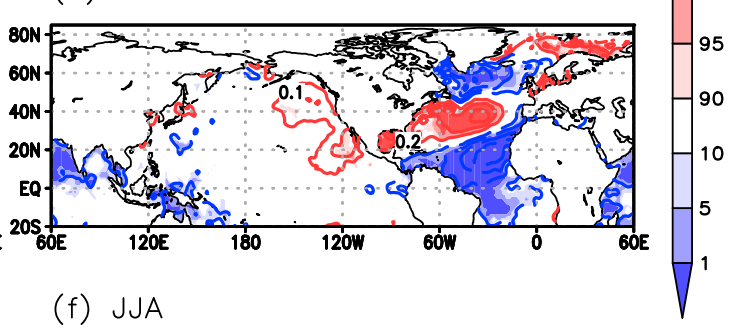

(f) JJA

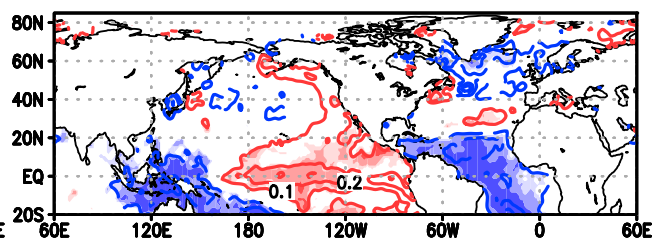

FIG. 8. Sea surface temperatures regressed on the DJF-mean NAO for the 25-yr period from 1966 to 1990 (contours). (a) DJF-, (b) MAM-, and (c) JJA-mean SSTs. (d)-(f) As in (a)-(c), but for the 25-yr period 1991-2015. The contour interval is $0.1 \mathrm{~K}$. The zero contour is omitted. Statistical significance is assessed by the 10000 -member Monte Carlo simulation (shading). Correlation values of which percentiles are greater (less) than $90 \%(10 \%), 95 \%$ $(5 \%)$, and $99 \%(1 \%)$ are shaded in gradually darker red (darker blue) color. 
(1966-1990)

(a) DJF

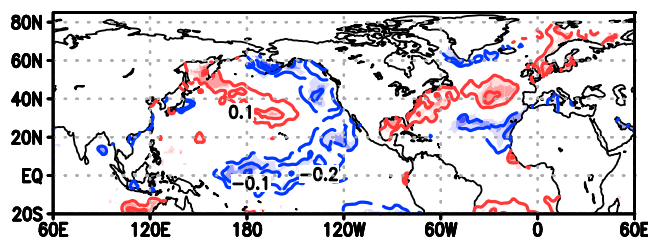

(b) MAM

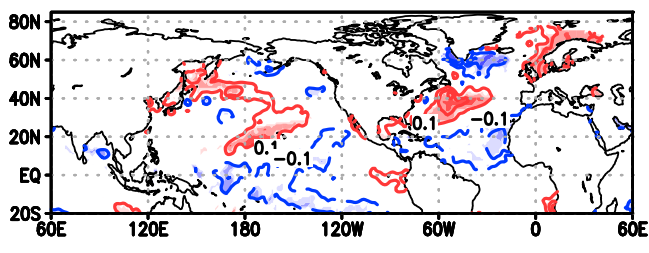

(c) JJA

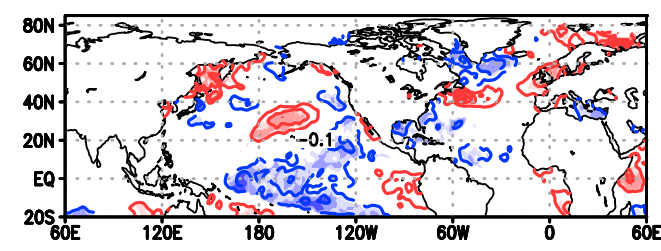

$(1991-2015)$

(d) DJF

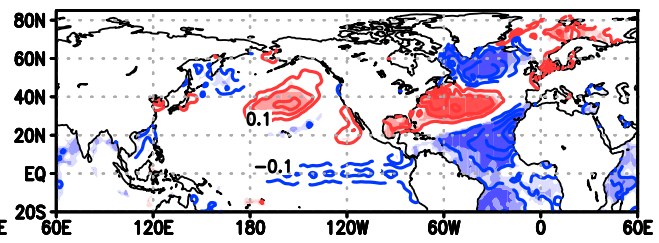

(e) MAM
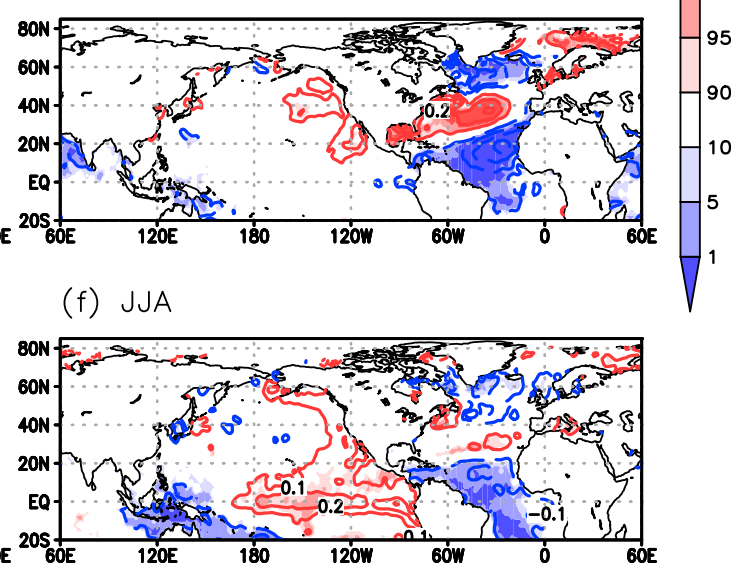

FIG. 9. As in Fig. 8, but for the detrended data. The trend is calculated for each period of 1966-90 and 1991-2015 separately.

coefficients of SST in the Norwegian and Barents Seas last until the following summer, while the tropical North Atlantic negative coefficients are weak in spring and almost diminish in summer (Figs. 8b,c). On the contrary, in the recent period, the tripole signal in winter is strong and remains until spring (Figs. 8d,e). However, it becomes negligible in summer except for the tropical region (Fig. 8f). Negative coefficients in the tropical North Atlantic are larger and last longer, until summer. In the recent period (1991-2015), the winter NAO and summer tropical North Atlantic SST averaged over the $0^{\circ}-20^{\circ} \mathrm{N}, 60^{\circ}-20^{\circ} \mathrm{W}$ region have a stronger correlation $(r=-0.51)$. Otomi et al. (2013) advocate that the persistent SST anomaly in the tropical North Atlantic played a crucial role for the polarity change from the positive AO (NAM) in the winter of 2010 to the negative NAM in the following summer. On the other hand, the summer correlation does not exist in the early period. Chen et al. (2015) also pointed out this interdecadal change in the relationship between winter NAO and northern tropical Atlantic SST, which is consistent with our results.

In general, SST exhibits the warming trend and the winter NAO also exhibits the increasing trend from the mid-1960s to the 1990s. These trends might cause a spurious correlation. To remove the effect of the trend, the regression maps using detrended data both for winter NAO and SST are shown in Fig. 9. Signals over the Atlantic are similar, while signals over the Indian Ocean and western Pacific become weak after removing trends. Signals over the Indian Ocean and western Pacific partly come from the trends. On the other hand, Atlantic signals are mainly due to the interannual variations.

Over the Norwegian Sea and the Barents Sea, where the winter ocean mixed layer is deep (Deser et al. 2003), the regression coefficient of SST persists until summer for the early period (Figs. 8a-c), while it diminishes in summer for the recent period (Fig. 8f). This feature does not change after removing trends (Fig. 9). Interseasonal persistency of SST over the Norwegian Sea and the Barents Sea was examined. To be more specific, we calculate lagged correlation coefficients of the regional-mean DJF-mean SST with the SSTs in the following months using detrended data for the early and recent period, separately. We found winter-tosummer persistency in the early period is high, while it is almost zero in the recent period (not shown). So the interseasonal persistency is much larger in the early period. This high persistency of SST anomaly over the region probably contributes to the good seasonal linkage in the early period. 

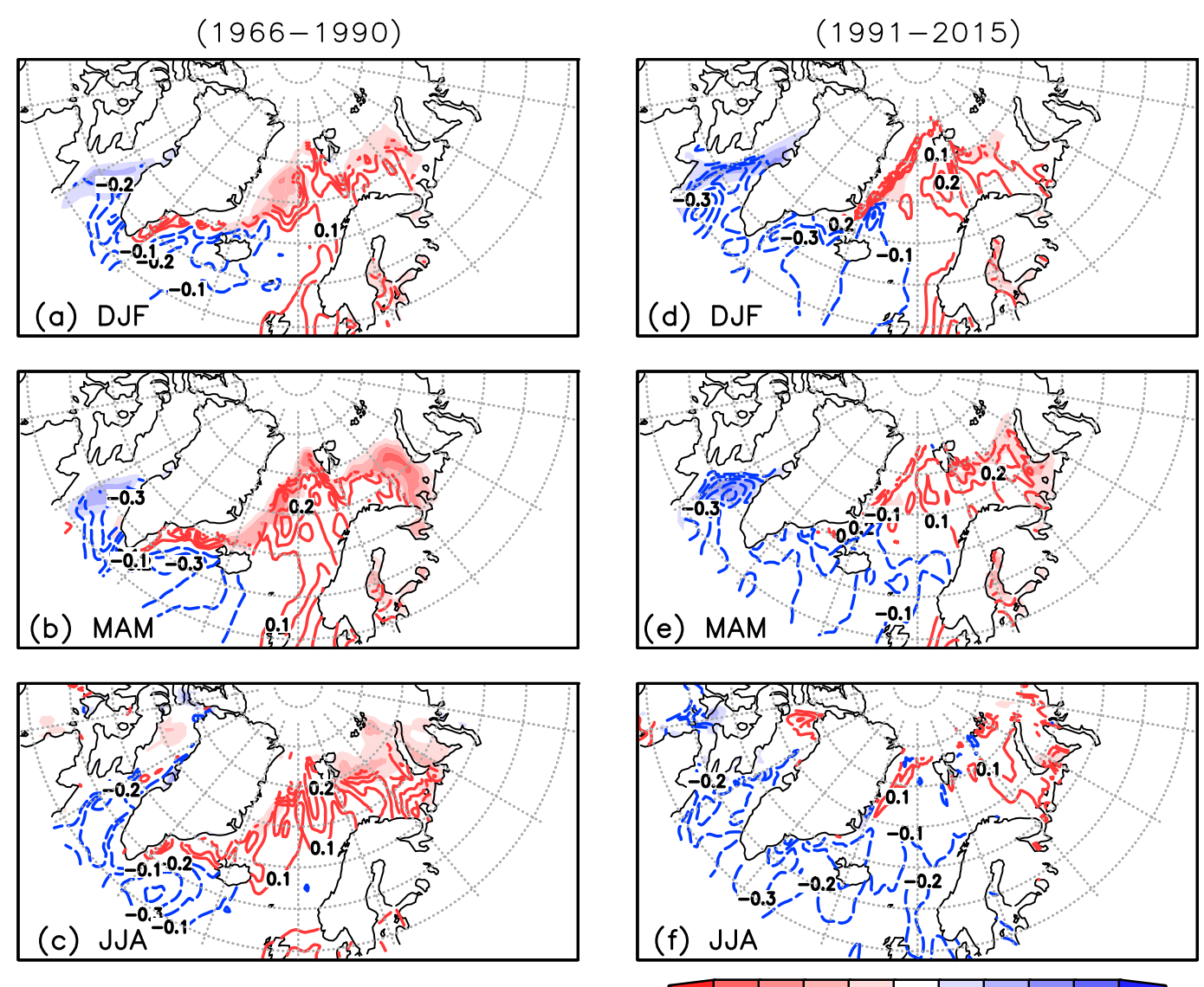

FIG. 10. Sea ice concentration (shaded; \%) and SST (contours; K) regressed on the DJF-mean NAO for the 25-yr period from 1966 to 1990. (a) DJF, (b) MAM, and (c) JJA means. (d)-(f) As in (a)-(c), but for the 25-yr period from 1991 to 2015. Negative (positive) values for sea ice concentration are shown in red (blue). The contour interval for SST is $0.1 \mathrm{~K}$. Positive (negative) contours are drawn in red (blue). Zero contours are omitted.

Maps of sea ice concentration regressed on the DJFmean NAO for the two periods are shown in Fig. 10. In winter, sea ice concentration over the North Atlantic and the Barents-Kara Sea region shows a negative value, while that to the west of Greenland shows a positive value. The signal over the North Atlantic and the Barents-Kara Sea region persists until summer in the early period, while that in the recent period diminishes in summer (cf. Figs. 10c and 10f). The similar feature can be seen in detrended maps (not shown). The interseasonal persistency of sea ice from winter to summer becomes lower in the recent period than that in the early period. The sea ice thinning (Kwok and Rothrock 2009) and the resultant vulnerability of the sea ice to the summer wind forcing (Ogi et al. 2010) in the recent period could reduce the winter-to-summer persistency of Arctic sea ice while these factors are irrelevant to the early period.

These suggest a possibility that this kind of difference in the seasonal persistency/evolution of the northern and tropical Atlantic SSTs and sea ice over the Arctic Ocean is a key for the decadal evolution of the wintersummer linkage.

\section{e. Changes in background climatological SST}

There might be changes in background climatological SST between two periods. Figure 11a shows the difference in the 25-yr mean annual SST between two 25-yr periods. Generally, SSTs in the recent period are warmer than those in the early period, reflecting global warming. In particular, SSTs in the North Atlantic show large warmings, while those in the South Atlantic show small warmings. Recalling the 25 -yr sliding correlation results (Fig. 1), the seasonal linkage is also weaker during the period before mid-1960. The differences between the early 25 -yr period and the earlier $15-\mathrm{yr}$ (1950-65) period indicate that SSTs in the North Atlantic show large cooling, while those in the South Atlantic show slight warming (Fig. 11b). Figure 11 suggests that the seasonal linkage becomes stronger when 

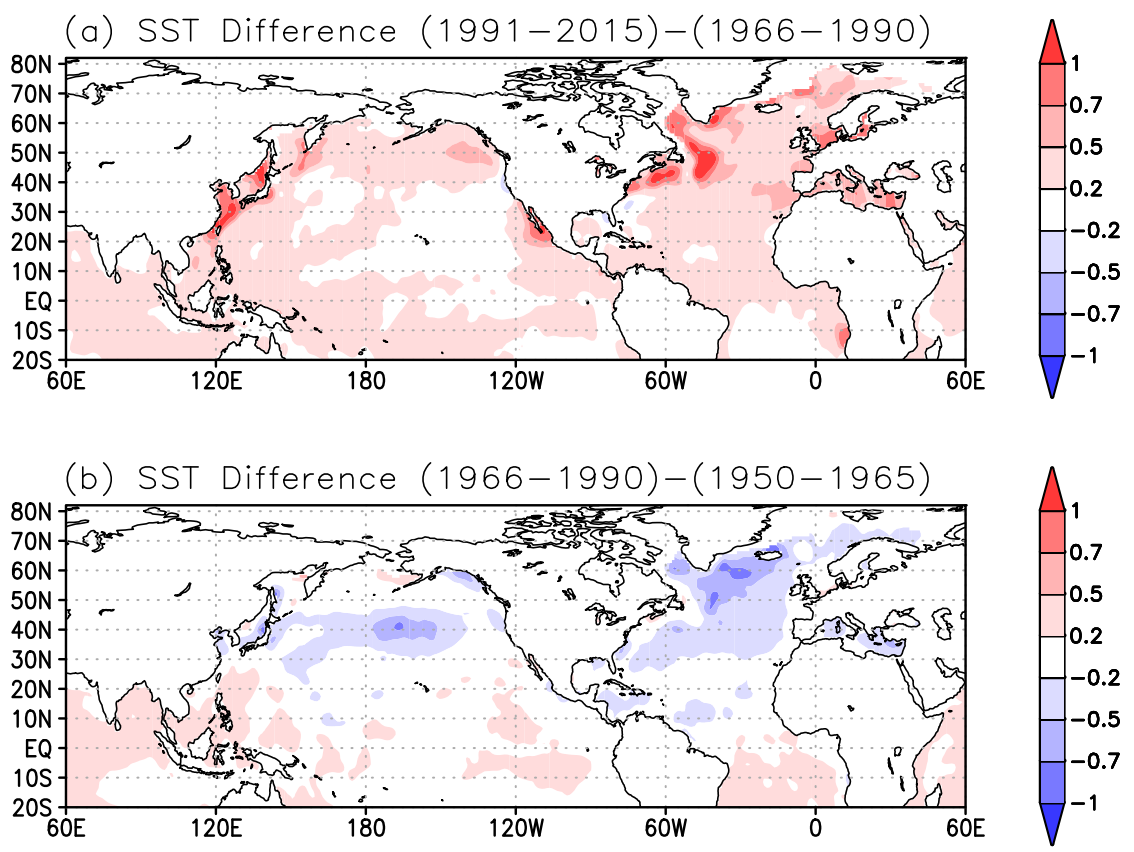

FIG. 11. The change in annual-mean climatological SST between two periods. (a) SST difference between 1991-2015 and 1966-90. (b) SST difference between 1966-90 and 1950-65.

negative (positive) SST anomalies reside in the North (South) Atlantic. This north-south seesaw of the Atlantic SST is known as the AMO (e.g., Enfield et al. 2001; Knight et al. 2006; Ting et al. 2014). Comparison of the low-passed (11-yr moving average) AMO with the seasonal linkage (C25: 25-yr sliding correlation between winter NAO and summer NAM) reveals that there is a strong correlation between the two (Fig. 12). The correlation coefficient between the low-pass AMO index and the seasonal linkage is -0.936 . The effective decorrelation time is estimated to be about 7 years (Metz 1991), and the effective sample size is 6 for $42-y r$ data for $\mathrm{C} 25$ and AMO. Thus, the correlation coefficient of -0.936 is statistically significant at the $99 \%$ level. This feature suggests the possibility that AMO is not a mere forcing factor of winter and summer NAO/NAM but rather a modifier of the linkage between them. However, the mechanism behind the relation is not clear and further studies are needed.

\section{f. Analyses of CESM simulation data}

It is well known that internal climate variability is large. Thus, the seasonal link can arise from internal climatic variability alone. To examine this possibility, we analyze the 2600-yr preindustrial CESM-AGCM control simulation and the $1800-y r$ preindustrial control simulation with the CESM-CGCM. In the 2600-yr AGCM control experiment, boundary forcings such as the SST and sea ice are prescribed as the climatological annual cycle and no interannual variations are given. Because of this experimental setting, memories should lie in the atmosphere and land. The seasonal correlation between winter NAO and summer NAM is 0.034 , which is small and is barely significant at the $90 \%$ level $\left(T_{e}=1.0 \mathrm{yr}\right)$. It suggests the role of land processes such as snow and soil moisture for the seasonal link is small.

In the 1800-yr CGCM preindustrial control experiment, ocean and sea ice interact with the atmosphere. Thus, memories lie also in the ocean and sea ice. The seasonal correlation between winter NAO and summer NAM is 0.104 , which is small, but significant at the 99.99\% level ( $t$ value is 4.5 ). Therefore, the seasonal linkage is unlikely to have arisen purely by chance. It is also suggested ocean and/or sea ice should work as a climatic memory for the winter-to-summer linkage.

We calculated the AMO defined by area-averaged Atlantic SST over $0^{\circ}-60^{\circ} \mathrm{N}$. The amplitude of simulated AMO (i.e., amplitude of the SST anomaly) is about half of the observed one. The correlation between the 25 -yr sliding correlation between the winter NAO and the summer NAM (C25) and the 11-yr moving AMO for the total period is -0.01 , which is negative, but too small. Further studies are needed for the AMO association.

We also calculate the 25-yr sliding correlation (C25) and examine the probability distribution of $\mathrm{C} 25$ (Fig. 13) both for AGCM and CGCM preindustrial control simulations. It is confirmed that internal climate variability is so large that even negative $\mathrm{C} 25$ takes place frequently. 

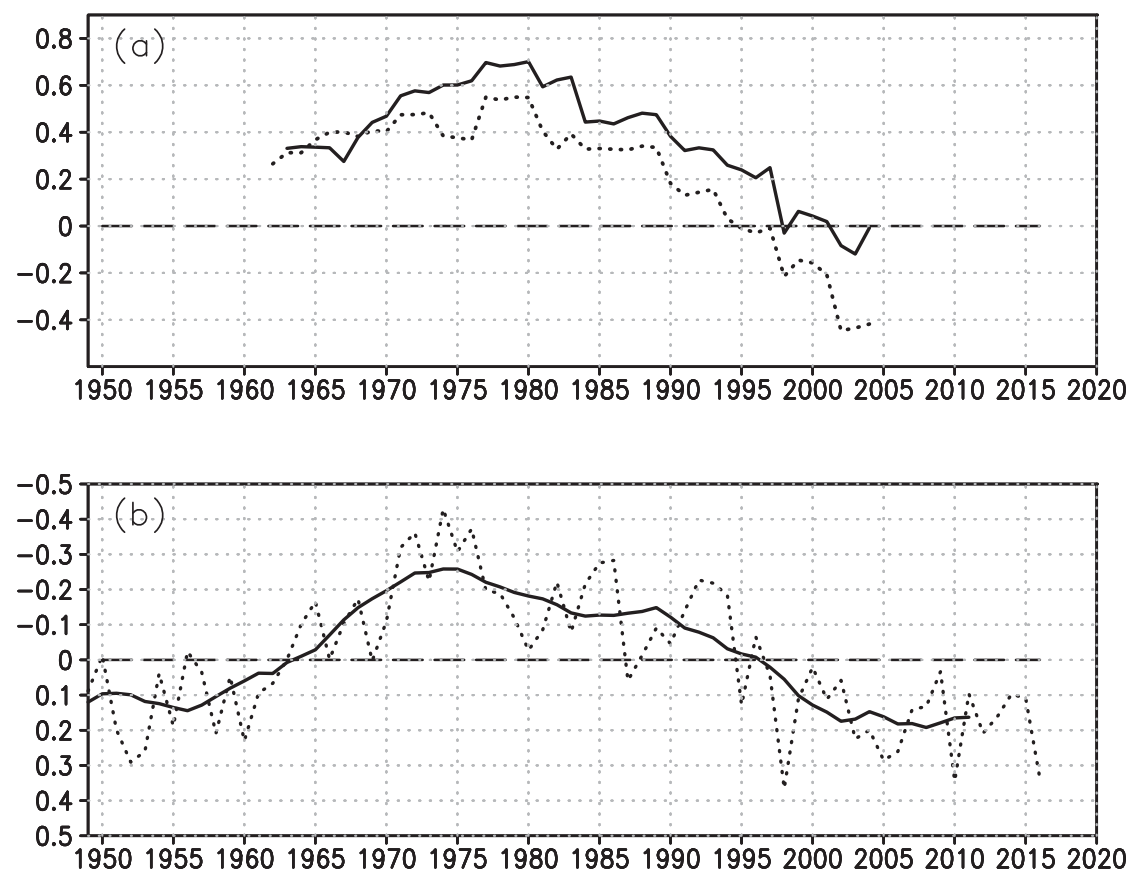

FIG. 12. The seasonal linkage and the Atlantic multidecadal oscillation (AMO). (a) Reproduction of Fig. 1b. The 25-yr sliding correlation coefficient between the winter NAO index and the following summer NAM index (black solid line) and the same correlation coefficient between the winter NAM and the following summer NAM index (black dotted line). Reproduced for easy comparison with the AMO time series. (b) AMO time series. The dotted line shows the annual-mean AMO index and the solid line shows its 11-yr running mean. The AMO index is inverted for easy comparison with the seasonal linkage.

The probability distribution is almost symmetric with zero. The probability of positive $\mathrm{C} 25$ is about $57 \%$. In the CGCM case (Fig. 13b), the probability distribution is shifted toward a positive side and the probability of positive $\mathrm{C} 25$ is about $72 \%$. It again suggests oceanatmosphere coupling is indispensable for the seasonal linkage.

The observed correlation (C25) in 1966-90 is higher than 0.6 (see Fig. 1b), while the correlation higher than 0.6 never occurs even in the CGCM simulations for 1800 years. This suggests that anthropogenic and/or natural external forcings also play a role in seasonal linkage.

Next, the large ensemble historical simulation for 1920-2005 with 35 members is analyzed. In this historical experiment, external forcings such as greenhouse gases, aerosols, and ozone are prescribed according to observations. The correlation coefficient between winter NAO and summer NAM for the ensemble mean and for total period (86 years) is 0.253 , which is significant at the $95 \%$ level. Although the correlation is not so high and nonstationary, it suggests the physical reality of the seasonal linkage. Time series of the seasonal linkage for ensemble mean is shown in Fig. 14 together with each ensemble. The ensemble mean shows nonstationary linkage during the period, though the timing of good and poor period does not completely agree with the observation. Further analysis is left for future studies.

\section{Summary and discussion}

We analyzed the relation between the winter NAO and the following summer circulation, particularly the summer NAM. The correlation between the winter NAO and the summer NAM is positive from the mid1960s to the 1980s, but after around 1990 the correlation becomes small or negative. Thus, during the past six decades, a clear winter-to-summer seasonal linkage in the early period broke down in the recent decades. During the early good-linkage period from the mid1960s to the 1980s, the winter NAM signature shows a strong troposphere-stratosphere coupling, while the coupling became weak during the recent poor-linkage period. During the early good-linkage period, the nearsurface temperature in northern Eurasia shows a long persistency until summer and the summer anomaly patterns in the lower-tropospheric temperature and 500-hPa geopotential height fields are annular, which resemble summer NAM patterns. On the other hand, 
(a) AGCM

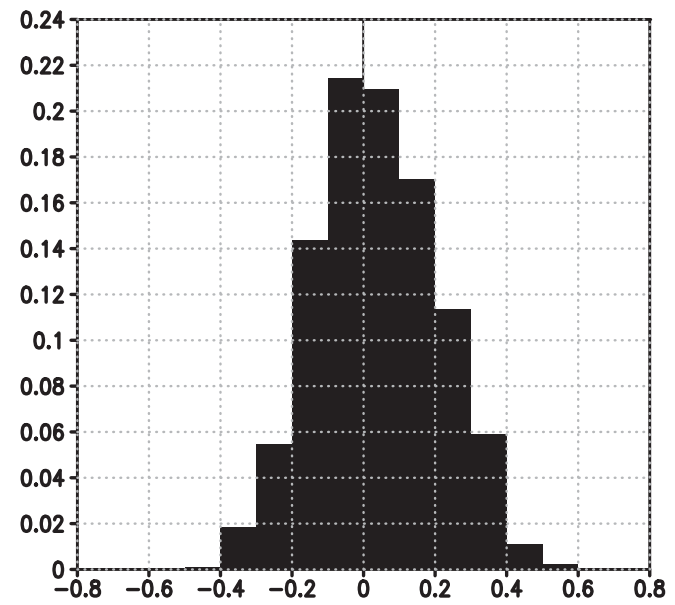

(b) CGCM

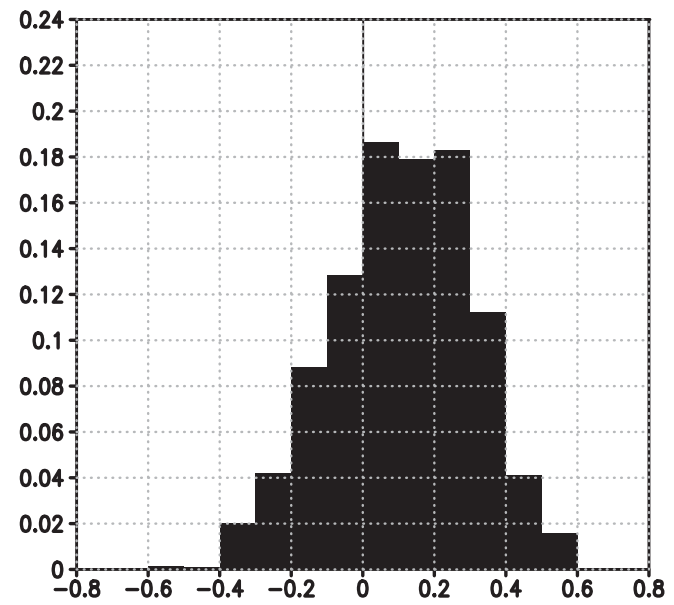

FIG. 13. Probability distribution of the 25-yr sliding correlation coefficient between the winter NAO index and the following summer NAM index for (a) the 2600-yr preindustrial control simulation with an AGCM and (b) the 1800 -yr preindustrial control simulation with a CGCM. The bin width is 0.1 for both panels.

during the recent poor-linkage period, the signal becomes weak in spring and diminishes in summer.

The disappearance of the stratospheric persistency of the signals related to winter NAO in the recent period is consistent with the previous study (Kuroda et al. 2008), considering climatic decline of the solar activity. In addition, the summer ozone anomalies in the extratropical lower stratosphere in the early period are localized around $60^{\circ} \mathrm{N}$, while those in the recent period are spread broadly. The localized heating in the lower stratosphere might trigger the change in the lower-tropospheric circulation through a change in synoptic wave activity (Nakamura et al. 2009).
During the early good-linkage period from the mid1960s to the 1980s, the high-latitude North Atlantic SST and the Arctic sea ice signal show a long memory, while the signal diminishes in summer during the recent poorlinkage period. Overall decline of high- to midlatitude persistency of the surface boundary conditions such as SST and sea ice in the recent period probably contributes to the breakdown of the seasonal linkage. However, the mechanism that connects the persistency of the boundary condition and summer circulation has not been clarified yet. On the contrary, the tropical North Atlantic SST anomaly has a longer memory in the recent decades, which may change the polarity of the NAM

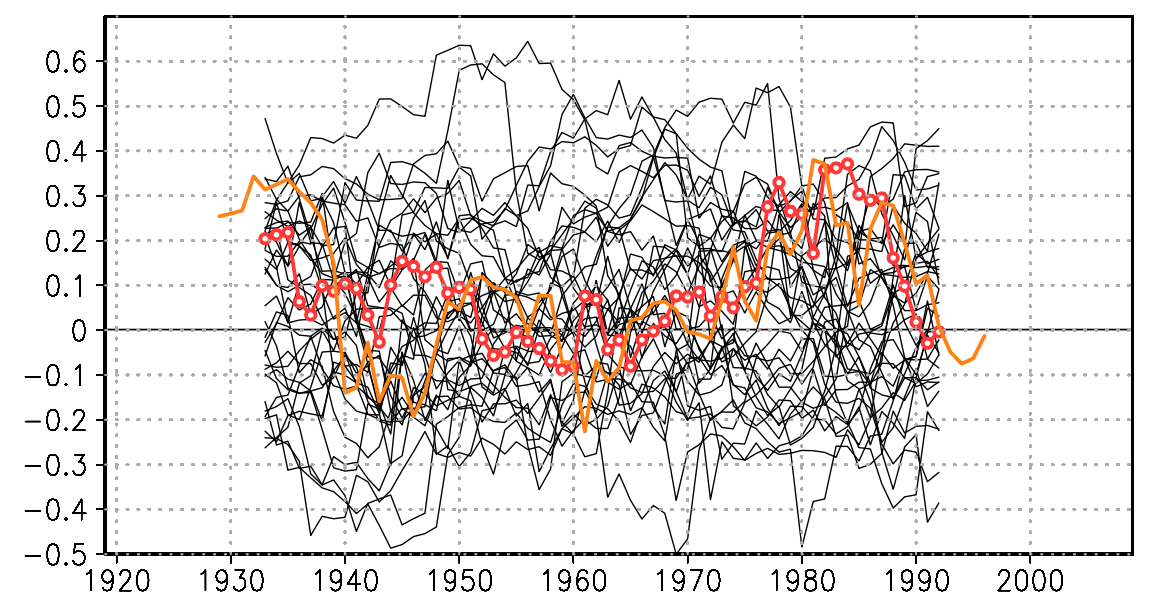

FIG. 14. Time series of 25-yr sliding correlation coefficient (C25; red line with open circles) between the winter NAO index and the following summer NAM index of the ensemble mean from the twentieth-century experiment (1920-2005; 35 members) with the CESM. C17 is also plotted (orange line). In addition, C25 for each member is plotted (black lines). 
from winter to summer. The negative NAO is associated with warm SST anomalies over the tropical North Atlantic in winter. For summer SST conditions with negative NAO anomalies in the preceding winter, Otomi et al. (2013) examined the atmospheric response to a heat source over the tropical North Atlantic by conducting numerical experiments. Then, they showed that the response has a large projection on to a positive summer NAM pattern.

Before the mid-1960s, the seasonal linkage is also insignificant. This poor linkage cannot be explained solely by solar activity or ozone. The seasonal linkage seems to be associated with the AMO. In the negative phase of the AMO (i.e., 1966-90) the seasonal linkage is good, while the linkage is poor in the positive phase of the AMO (i.e., before 1965 and after 1991). However, the mechanism behind the relation is not clear.

The recent decline of the seasonal linkage might be related to the recent North Atlantic SST and sea ice persistency, recent reduced solar activity, positive AMO, and changes in external forcings. In any case, acknowledgment of the seasonal linkage and its decadal modulation is useful for seasonal forecasts.

Acknowledgments. KY and TN are supported by The Arctic Challenge for Sustainability (ArCS) project and the Belmont Forum. MO is supported by the Canada Excellence Research Chairs program. This study was partly supported by the Ministry of Education, Culture, Sports, Science and Technology through a Grant-in-Aid for Scientific Research (Grant 18K0373508). This paper is a contribution from the Arctic Science Partnership and ArcticNet.

\section{REFERENCES}

Ball, W. T., and Coauthors, 2018: Evidence for a continuous decline in lower stratospheric ozone offsetting ozone layer recovery. Atmos. Chem. Phys., 18, 1379-1394, https://doi.org/ 10.5194/acp-18-1379-2018.

Barnston, A. G., and R. E. Livezey, 1987: Classification, seasonality and persistence of low-frequency atmospheric circulation patterns. Mon. Wea. Rev., 115, 1083-1126, https://doi.org/10.1175/ 1520-0493(1987)115<1083:CSAPOL $>2.0 . C O ; 2$.

Chen, S., R. Wu, and W. Chen, 2015: The changing relationship between interannual variations of the North Atlantic Oscillation and northern tropical Atlantic SST. J. Climate, 28, 485504, https://doi.org/10.1175/JCLI-D-14-00422.1.

Clette, F., L. Svalgaard, J. M. Vaquero, and E. W. Cliver, 2014: Revisiting the sunspot number: A 400-year perspective on the solar cycle. Space Sci. Rev., 186, 35-103, https://doi.org/ 10.1007/s11214-014-0074-2.

Dee, D. P., and Coauthors, 2011: The ERA-Interim reanalysis: Configuration and performance of the data assimilation system. Quart. J. Roy. Meteor. Soc., 137, 553-597, https://doi.org/ 10.1002/qj.828.
Deser, C., M. A. Alexander, and M. S. Timlin, 2003: Understanding the persistence of sea surface temperature anomalies in midlatitudes. J. Climate, 16, 57-72, https://doi.org/10.1175/ 1520-0442(2003)016<0057:UTPOSS $>2.0 . \mathrm{CO} ; 2$.

Dragani, R., 2011: On the quality of the ERA-Interim ozone reanalyses: Comparisons with satellite data. Quart. J. Roy. Meteor. Soc., 137, 1312-1326, https://doi.org/10.1002/qj.821.

Enfield, D. B., A. M. Mestas-Nunez, and P. J. Trimble, 2001: The Atlantic multidecadal oscillation and its relation to rainfall and river flows in the continental U.S. Geophys. Res. Lett., 28 , 2077-2080, https://doi.org/10.1029/2000GL012745.

Ermolli, I., and Coauthors, 2013: Recent variability of the solar spectral irradiance and its impact on climate modelling. Atmos. Chem. Phys., 13, 3945-3977, https://doi.org/10.5194/ acp-13-3945-2013.

Folland, C. K., J. Knight, H. W. Linderholm, D. Fereday, S. Inesen, and J. H. Hurrell, 2009: The summer North Atlantic Oscillation: Past, present, and future. J. Climate, 22, 1082-1103, https://doi.org/10.1175/2008JCLI2459.1.

Hurrell, J. W., Y. Kushnir, G. Ottersen, and M. Visbeck, 2003: The North Atlantic Oscillation: Climatic Significance and Environmental Impact. Geophys. Monogr., Vol. 134, Amer. Geophys. Union, 279 pp.

Kalnay, E., and Coauthors, 1996: The NCEP/NCAR 40-Year Reanalysis Project. Bull. Amer. Meteor. Soc., 77, 437-471, https://doi.org/10.1175/1520-0477(1996)077<0437: TNYRP $>2.0 . \mathrm{CO} ; 2$.

Kay, J. E., and Coauthors, 2015: The Community Earth System Model (CESM) large ensemble project: A community resource for studying climate change in the presence of internal climate variability. Bull. Amer. Meteor. Soc., 96, 1333-1349, https://doi.org/10.1175/BAMS-D-13-00255.1.

Knight, J. R., C. K. Folland, and A. A. Scaife, 2006: Climate impacts of the Atlantic Multidecadal Oscillation. Geophys. Res. Lett., 33, L17706, https://doi.org/10.1029/2006GL026242.

Kuroda, Y., K. Yamazaki, and K. Shibata, 2008: Role of ozone in the solar cycle modulation of the North Atlantic Oscillation. J. Geophys. Res., 113, D14122, https://doi.org/10.1029/ 2007JD009336.

Kwok, R., and D. A. Rothrock, 2009: Decline in Arctic sea ice thickness from submarine and ICESat records: 1958-2008. Geophys. Res. Lett., 36, L15501, https://doi.org/10.1029/ 2009GL039035.

Metz, W., 1991: Opimal relationship of large-scale flow patterns and the barotropic feedback due to high-frequency eddies. J. Atmos. Sci., 48, 1141-1159, https://doi.org/10.1175/ 1520-0469(1991)048<1141:OROLSF $>2.0 . C O ; 2$.

Nakamura, T., H. Akiyoshi, and Y. Yamashita, 2009: Influence of lower stratospheric ozone variation on tropospheric temperature and mean meridional circulation in the Northern Hemisphere summer. Geophys. Res. Lett., 36, L14701, https:// doi.org/10.1029/2009GL038563.

Ogi, M., Y. Tachibana, and K. Yamazaki, 2003a: Impact of the wintertime North Atlantic Oscillation (NAO) on the summertime atmospheric circulation. Geophys. Res. Lett., 30, 1704, https://doi.org/10.1029/2003GL017280.

_ , K. Yamazaki, and Y. Tachibana, 2003b: Solar cycle modulation of the seasonal linkage of the North Atlantic Oscillation (NAO). Geophys. Res. Lett., 30, 2170, https://doi.org/10.1029/ 2003 GL018545.

,-- , and - 2004: The summertime annular mode in the Northern Hemisphere and its linkage to the winter mode. J. Geophys. Res., 109, D20114, https://doi.org/10.1029/2004JD004514. 
,-- , and - 2005: The summer northern annular mode and abnormal summer weather in 2003. Geophys. Res. Lett., 32, L04706, https://doi.org/10.1029/2004GL021528.

_ - — , and J. M. Wallace, 2010: Influence of winter and summer surface wind anomalies on summer Arctic sea ice extent. Geophys. Res. Lett., 37, L07701, https://doi.org/10.1029/2009GL042356.

Otomi, Y., Y. Tachibana, and T. Nakamura, 2013: A possible cause of the AO polarity reversal from winter to summer in 2010 and its relation to hemispheric extreme summer weather. Climate Dyn., 40, 1939-1947, https://doi.org/10.1007/s00382-012-1386-0.

Pan, L.-L., 2005: Observed positive feedback between the NAO and the North Atlantic SSTA tripole. Geophys. Res. Lett., 32, L06707, https://doi.org/10.1029/2005GL022427.

Rayner, N. A., D. E. Parker, E. B. Horton, C. K. Folland, L. V. Alexander, D. P. Rowell, E. C. Kent, and A. Kaplan, 2003: Global analyses of sea surface temperature, sea ice, and night marine air temperature since the late nineteenth century. J. Geophys. Res., 108, 4407, https://doi.org/10.1029/2002JD002670.

Rottman, G., 1999: Solar ultraviolet irradiance and its temporal variation. J. Atmos. Sol.-Terr. Phys., 61, 37-44, https://doi.org/ 10.1016/S1364-6826(98)00114-X.

Tachibana, Y., T. Nakamura, H. Komiya, and M. Takahashi, 2010: Abrupt evolution of the summer Northern Hemisphere annular mode and its association with blocking. J. Geophys. Res., 115, D12125, https://doi.org/10.1029/2009JD012894.

Thompson, D. W. J., and J. M. Wallace, 2000: Annular modes in the extratropical circulation. Part I: Month-to-month variability. J. Climate, 13, 1000-1016, https://doi.org/10.1175/ 1520-0442(2000)013<1000:AMITEC > 2.0.CO;2.
, and - 2001: Regional climate impacts of the Northern Hemisphere annular mode. Science, 293, 85-89, https:// doi.org/10.1126/science.1058958.

,-- , and G. C. Hegerl, 2000: Annular modes in the extratropical circulation. Part II: Trends. J. Climate, 13, 1018-1036, https://doi.org/10.1175/1520-0442(2000)013<1018:AMITEC >2.0. $\mathrm{CO} ; 2$.

Ting, M., Y. Kushner, and C. Li, 2014: North Atlantic Multidecadal SST Oscillation: External forcing versus internal variability. J. Mar. Syst., 133, 27-38, https://doi.org/10.1016/ j.jmarsys.2013.07.006.

Titchner, H. A., and N. A. Rayner, 2014: The Met Office Hadley Centre sea ice and sea surface temperature data set, version 2:1. Sea ice concentrations. J. Geophys. Res. Atmos., 119, 2864-2889, https://doi.org/10.1002/2013JD020316.

Visbeck, M., E. P. Chassignet, R. G. Curry, T. L. Delworth, R. R. Dickson, and G. Krahmann, 2003: The ocean's response to North Atlantic Oscillation variability. The North Atlantic Oscillation: Climatic Significance and Environmental Impact, Geophys. Monogr., Vol. 134, Amer. Geophys. Union, 113145, https://doi.org/10.1029/134GM06.

Wilks, D. S., 2016: "The stippling shows statistically significant grid points": How research results are routinely overstated and overinterpreted, and what to do about it. Bull. Amer. Meteor. Soc., 97, 2263-2273, https://doi.org/10.1175/BAMS-D-15-00267.1.

Wu, Z., J. Li, Z. Jiang, J. He, and X. Zhu, 2012: Possible effects of the North Atlantic Oscillation on the strengthening relationship between the East Asian summer monsoon and ENSO. Int. J. Climatol., 32, 794-800, https://doi.org/10.1002/joc.2309. 